\title{
Fluid dynamics of a post-combustion chamber in electric arc steelmaking plants
}

\author{
L. Labiscsak ${ }^{1}$, G. Straffelini ${ }^{1}$, C. Corbetta ${ }^{2} \&$ M. Bodino ${ }^{2}$ \\ ${ }^{I}$ Department of Materials Engineering and Industrial Technologies, \\ University of Trento, Italy \\ ${ }^{2}$ Stg Group SpA, Italy
}

\begin{abstract}
In the present work, a complete three dimensional fluid dynamics simulation of reacting fluid flow in post-combustion chamber of an electric arc furnace is presented. The chemical composition of the simulated off-gases was representing typical crucial load. The gap (where oxygen enters to combust hydrogen and carbon monoxide) size was an independent variable. The optimal gap size is desirable: if the gap size is too large, the thermal efficiency diminishes. On the other hand, if the chosen gap size is too small, oxygen deficiency occurs, which lead to incomplete combustion of carbon monoxide and hydrogen. Herein established, that by means of CFD calculation, the optimal gap size can be evaluated for a particular steelmaking furnace.
\end{abstract}

Keywords: steelmaking, post-combustion, CFD.

\section{Introduction}

The steel production by electric arc furnace (EAF) from scrap metal is widely used technique. During the production of steel considerable amount of combustible gases are formed such as carbon monoxide and hydrogen, which are extracted directly through the fourth hole, which is placed on the water-cooled furnace roof. As a result, the furnace inner is depressurized, which helps to minimize the harmful gas emissions, and air enters the furnace from the factory's ambient. The flow rate of the penetrating air (usually called false air), is defined by: the suction flow-rate of the direct evacuation system (DES), the design of the furnace inner and the amount of generated gases in the furnace. Consequently, the operation of the DES influences the mass and energy balance of the EAF. 
The oxygen in the false air oxidizes the carbon monoxide and hydrogen in the furnace. However, up to $10 \%$ (occasionally $30 \%$ ) of carbon monoxide and $10 \%$ of hydrogen $[1,2]$ remain unburned and leave the free board via the fourth hole. Since, these reactions are highly exothermic; the complete oxidation of the abovementioned gases is desired in order to maximize the thermal efficiency of the EAF.

For this reasons, the primary line is equipped with a gap, where fresh air may enter from the factory's ambient and mix with off-gases. The oxidation takes place in the post-combustion chamber. The size of the gap can be changed and is an important operation parameter. If the gap size is too large, the temperature will drop, leading to lower thermal efficiency and lower reaction rates. By contrast, the smaller the gap, the higher the temperature, this enhances the decomposition of carbon dioxide. A small gap size also lead to oxygen deficiency, hence the complete oxidation is inhibited. The walls of the postcombustion chamber are water-cooled, which enhances efficiency and desirable for protecting filtering devices from high temperature as well. As a result, the direct evacuation system plays a dominant role in the steelmaking process.

CFD calculations are increasingly used in development and improvement of steelmaking processes [3]. Li et al. [2] presented a three-dimensional (3D) CFD simulation about the furnace freeboard. Chattopadhyay et al. [4, 5] recently published review about the application of CFD simulation in the field of ironand steelmaking. Furthermore, Mazudmar and Evans [6] dedicated a complete section in their book about CFD relevance in the field of steelmaking. Kirschen et al. [1] published an analytical model about the dedusting system of the furnace and compared its results to experimental measurements. Due to the huge temperature difference between the flame and surroundings, the radiation modeling has a great importance. Habibi et al. [7] interpreted CFD simulation about $\mathrm{CH}_{4} / \mathrm{H}_{2}$ /air flames with different radiation heat exchange models and compared the results to adiabatic flame.

In the present investigation, a complete $3 \mathrm{D}$ numerical simulation of reacting flow, energy and concentration fields of a post-combustion chamber were carried out. Many simulation routines were used to find the suitable models for the best accuracy. In order to optimize the operation of the post-combustion chamber, the size of the gap was changed and conversions along with thermal efficiencies of the chamber were calculated simultaneously.

\section{Modeling of post-combustion chamber}

\subsection{Geometry and computational grid}

A newly designed post-combustion chamber was simulated. The geometry of the simulated reactor is depicted in Figure 1 and the relevant chamber specifications are listed in Table 1.

The off-gas with hydrogen and carbon monoxide enters via the inlet and mixes with fresh air coming from the ambient through the gap. The size of the gap is an independent variable, i.e., a design parameter (Figure 2). 
Table 1: Chamber specification.

\begin{tabular}{|l|l|}
\hline Total volume & $388,7 \mathrm{~m}^{3}$ \\
\hline Inlet area & $2,9 \mathrm{~m}^{2}$ \\
\hline Outlet area & $6,6 \mathrm{~m}^{2}$ \\
\hline Water-cooled surface & $430,0 \mathrm{~m}^{2}$ \\
\hline
\end{tabular}



Figure 1: Geometry of the post-combustion chamber.

Consequently, the selected operating parameters define the mixing ratio, i.e. the ratio between the airflow through the gap $\left(\dot{\mathrm{V}}_{\text {air }}\right)$ and the off-gases from the $\operatorname{EAF}\left(\dot{\mathrm{V}}_{\mathrm{EAF}}\right)$.

The geometry was discretized by tetrahedral elements, Figure 3. The computational mesh was unstructured and conformal. Local mesh refinements were applied in regions where steep gradients of the dependent variables (temperature, velocity, pressure) were expected.

The mesh was also refined in reacting zone (where carbon monoxide, hydrogen and oxygen mix) where high gradients of concentrations are expected. Steep temperature gradient was likewise expected in reacting zone due to the 


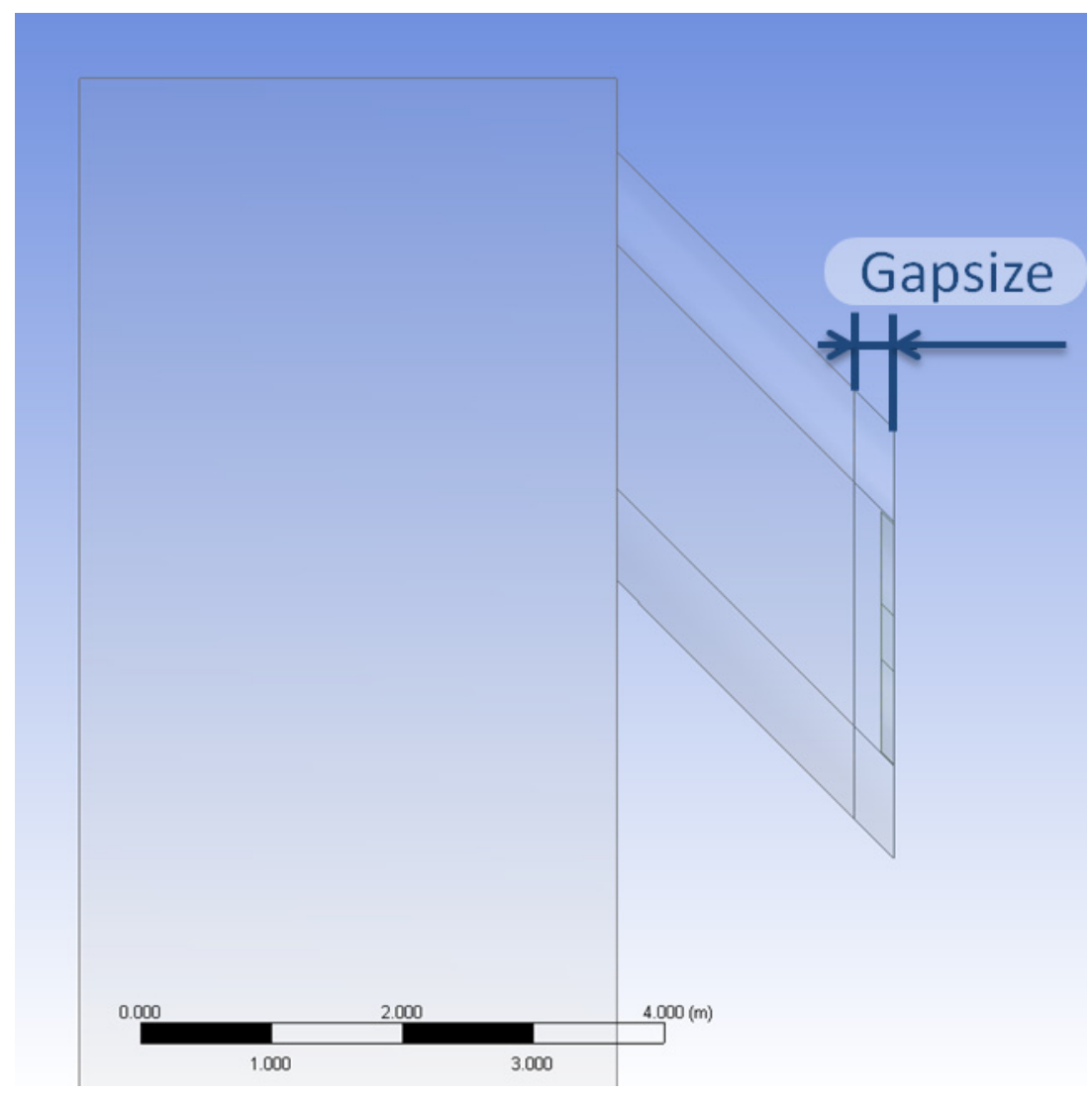

Figure 2: The gap size controls the mixing ratio (see text for definition).

exothermic reactions. The number of the cells was typically between 500.000 and 650.000 , depending on the gap size. Since the present investigation is a preliminary study, the mesh independent study was not presented herein nevertheless it is currently in progress.

The convergence criteria of CFD calculations were achieved and the adopted residuals for each equation are listed in Table 2 .

\subsection{Kinetic mechanism}

The following skeleton reactions were taken into account within the reacting flow:

$$
\begin{aligned}
2 \mathrm{H}_{2}+\mathrm{O}_{2} & \rightarrow 2 \mathrm{H}_{2} \mathrm{O} \\
2 \mathrm{CO}+\mathrm{O}_{2} & \leftrightarrow 2 \mathrm{CO}_{2}
\end{aligned}
$$






Figure 3: $\quad$ The discretized 3D domain.

Table 2: $\quad$ Adopted residuals for each equation.

\begin{tabular}{|l|l|}
\hline Equations & Residuals \\
\hline \hline Continuity & $1 \mathrm{E}-05$ \\
\hline Velocity $(\mathrm{x}, \mathrm{y}, \mathrm{z})$ & $1 \mathrm{E}-06$ \\
\hline Energy & $1 \mathrm{E}-06$ \\
\hline Turbulent kinetic energy $(\kappa)$ & $3 \mathrm{E}-06$ \\
\hline Turbulent dissipation rate $(\varepsilon)$ & $5 \mathrm{E}-06$ \\
\hline DO intensity & $1 \mathrm{E}-06$ \\
\hline Species & $1 \mathrm{E}-06$ \\
\hline
\end{tabular}

Simplified, one-step reaction simulations give poor prediction about carbon monoxide and hydrogen content of the exiting gas and significantly over predict the carbon monoxide content at the outlet. Therefore, detailed kinetic mechanism was implemented and comprises 12 species and 37 reactions and based on the studies of Cuoci et al. [8]. The used rate constants are in good match with experimental measurements in wide range of temperature. The reacting flows were simulated by the Eddy dissipation concept (EDC) model [9], which allows for integrating the detailed chemical mechanisms into turbulent reacting flows. 
Non-Premixed Combustion (NPC) approach [10], and the Finite Rate/Eddy Dissipation approach were also tested, however EDC model provided the most reliable results [11].

\subsection{Radiation modeling}

Thanks to the exothermic reactions in the chamber, the difference between fume's temperature and water-cooled walls is very large; hence, the heat transfer by radiation plays a dominant role. The approximation adopted in this study for radiation modeling is the Discrete-Ordinates approach, which is an accurate method [7]. It can handle wide range of optical thickness, at the price of a high computational cost. The absorbencies of the materials have a strong influence. The off-gas is mixture of gases, which have different absorption coefficients. Furthermore, the composition of the mixture changes rapidly along the chamber. Therefore, absorption coefficients must be handled carefully; the weighted-sumof-gray-gases model (WSGGM) was used, since it is a reasonable compromise between the oversimplified gray gas model and the complete model, which takes into consideration the specific absorption bands [12].

\subsection{Numerical scheme}

The governing equations for the mass, momentum, energy, chemical species and radiation were solved segregated and the SIMPLE method was used for pressurevelocity coupling. The non-linear equations were discretized implicitly by second-order upwind scheme. The standard $\kappa-\varepsilon$ model was used for turbulence modeling. As known, this model is widely used in CFD applications in the field of steelmaking, since it is a reasonable compromise between accuracy and computational cost [5]. The appropriate under-relaxation factors were set to find the convergence.

\subsection{Boundary conditions}

The selected boundary conditions are shown in Table 3. The listed data are input parameters, which were taken from literature data and experimental measurements. The evacuation is determined by the power of the fan in the primary line. The discharge flow rate was set to $230.000 \mathrm{Nm}^{3} / \mathrm{h}$.

Table 3: $\quad$ Implied boundary conditions.

\begin{tabular}{|l|l|l|l|}
\hline \multicolumn{2}{|l|}{ Inlet } & Gap \\
\hline Pressure & $-10 \mathrm{~Pa}$ & Pressure & $-10 \mathrm{~Pa}$ \\
\hline Temperature & $1523 \mathrm{~K}$ & Temperature & $473 \mathrm{~K}$ \\
\hline Chemical composition & Table 4. & Chemical composition & Table 4. \\
\hline Outlet & Walls \\
\hline Velocity & $23,6 \mathrm{~m} / \mathrm{s}$ & Temperature & $353 \mathrm{~K}$ \\
\hline
\end{tabular}


The selected concentration of the entering gas at the fourth hole and at the gap is listed in Table 4. These values represent a typical load during the melting period, which is the most crucial period from post-combustion point of view.

Table 4: Input data for chemical compositions. At the gap, pure air was assumed.

\begin{tabular}{|l|c|c|}
\hline Material & Inlet (\%) & Gap (\%) \\
\hline $\mathrm{CO}$ & 30 & 0 \\
\hline $\mathrm{CO}_{2}$ & 0 & 0 \\
\hline $\mathrm{H}_{2}$ & 10 & 0 \\
\hline $\mathrm{H}_{2} \mathrm{O}$ & 0 & 1 \\
\hline $\mathrm{O}_{2}$ & 0 & 21 \\
\hline $\mathrm{N}_{2}$ & 60 & 78 \\
\hline
\end{tabular}

\section{Results and discussion}

In our CFD calculations, the oxidation of carbon monoxide and hydrogen in the post-combustion chamber was simulated with three different gap sizes: 20, 30 and $40 \mathrm{~cm}$. The heat efficiency and the conversion rates were monitored at each geometry.

The heat transfer efficiency $(\eta)$ was evaluated from the ratio between the transferred heat via the water-cooled wall $\left(H_{\text {wall }}\right)$ and the sum of the entering heat $\left(H_{\text {in }}\right)$ and reaction heat $\left(H_{\text {react }}\right)$ :

$$
\eta=\frac{H_{\text {wall }}}{H_{\text {in }}+H_{\text {react }}}
$$

The reactions occur only in case of mixing of combustible gases and oxygen. Figure 4 showing the mass fraction of carbon monoxide and proves that the reactions take place at the very beginning of the post-combustion chamber. Consequently, the mixing can assumed very efficient. The calculated conversion factors are listed in Table 5.

It can be noted, that complete combustion of carbon monoxide and hydrogen occurred only in case of $40 \mathrm{~cm}$ gap size. When the gap size is $30 \mathrm{~cm}$, the conversion is almost satisfactory (Table 5). Nevertheless, in case of $20 \mathrm{~cm}$ gap size, there is not enough oxygen for the complete reaction. Therefore, the

Table 5: Results of the simulations: conversions and final contents of $\mathrm{CO}$ and $\mathrm{H} 2$ expressed in ppm.

\begin{tabular}{|c|c|c|c|c|}
\hline Gap size $(\mathrm{cm})$ & CO conversion & $\mathrm{H}_{2}$ conversion & $\mathrm{CO}(\mathrm{ppm})$ & $\mathrm{H}_{2}(\mathrm{ppm})$ \\
\hline 20 & 0,53 & 0,72 & 34300 & 6920 \\
\hline 30 & 0,97 & 0,99 & 1475 & 163 \\
\hline 40 & 0,99 & 1,00 & 64 & 0,34 \\
\hline
\end{tabular}



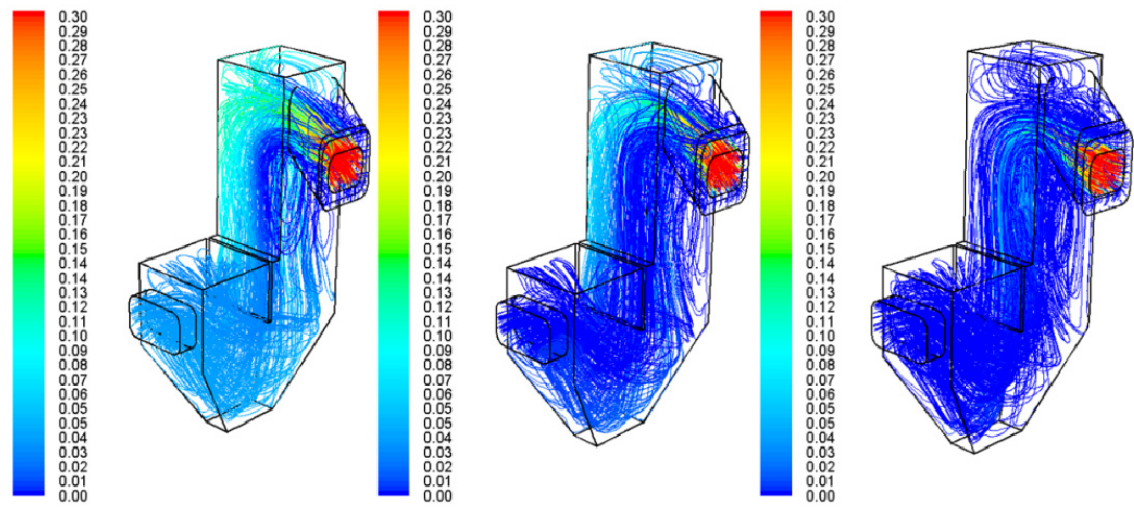

Figure 4: Carbon monoxide's mass fractions in the post-combustion chamber (color maps are scaled in mass fraction); gap sizes are 20, 30 and $40 \mathrm{~cm}$, from left to right respectively.

conversion rate of $\mathrm{H}_{2} / \mathrm{CO}$ remains low and its concentration at the exit is quite high.

In Table 6, the concentrations of the exiting gases are listed. The compositions of the leaving gases were compared to literature data [1] and experimental measurements, provided by the Stg Group Company. The calculated data match with the available data. The effect of the gap size on the oxygen content can be easily derived. The small gap size causes oxygen deficit and incomplete combustion.

Table 6: Results of the simulations: chemical composition of the exiting gas (expressed in mass percentage).

\begin{tabular}{|c|c|c|c|c|c|}
\hline Gap size $(\mathrm{cm})$ & $\mathrm{CO}(\%)$ & $\mathrm{CO}_{2}(\%)$ & $\mathrm{H}_{2}(\%)$ & $\mathrm{O}_{2}(\%)$ & $\mathrm{H}_{2} \mathrm{O}(\%)$ \\
\hline 20 & 3,43 & 6,01 & $6,92 \mathrm{E}-01$ & $2,90 \mathrm{E}-05$ & 16,2 \\
\hline 30 & 0,15 & 7,80 & $1,63 \mathrm{E}-02$ & 1,18 & 15,9 \\
\hline 40 & $6,47 \mathrm{E}-03$ & 7,30 & $3,41 \mathrm{E}-05$ & 2,67 & 14,8 \\
\hline
\end{tabular}

Thermal efficiencies are lower when the gap size is large and the oxygen excess also presents (Table 7). Moreover, large gap causes lower temperature at the outlet (Figure 5), which is desirable to avoid the damage of the polymer filters.

Table 7: The mixing ratio, thermal efficiency and the temperature of the exiting gas.

\begin{tabular}{|c|c|c|c|}
\hline Gap size $(\mathrm{cm})$ & Mixing Ratio & Thermal Efficiency $(\eta)$ & Outlet Temp. $(\mathrm{K})$ \\
\hline 20 & 1,34 & 0,65 & 1172 \\
\hline 30 & 2,09 & 0,62 & 1264 \\
\hline 40 & 2,32 & 0,60 & 1252 \\
\hline
\end{tabular}



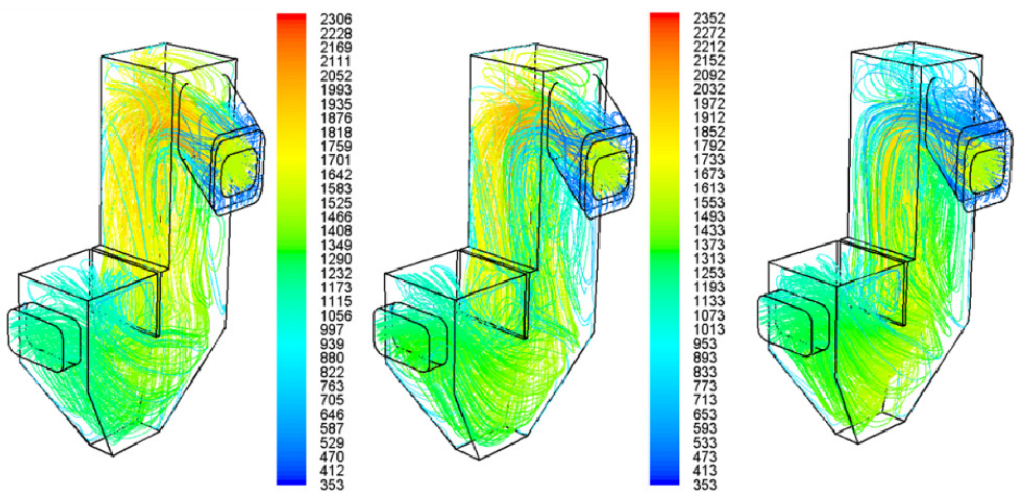

Figure 5: Gas temperature in the post-combustion chamber (color maps are scaled in Kelvin); gap sizes are 20,30 and $40 \mathrm{~cm}$, from left to right respectively.

Our results show, that the increase of the gap size reduces the emission of harmful gases due to the complete oxidation. In the meantime, the value of the thermal efficiency remains reasonably high.

From the fluid dynamic point of view, the selected geometry of the postcombustion chamber poses conflicting observations. From the one hand, the calculated path lines demonstrated a turbulent pattern of flow, with the creation of tortuous streamlines and recirculating zones. This is clearly due to the presence of sharp-edge corners, abrupt changes of direction and stagnate zones. All these factors do not help the smoothness of the flow, although help the settling of fine particles, which may present in the off-gas. On the other hand, this does not adversely affect the overall performance of the chamber, since mixing is enhanced.

\section{Conclusions}

In the present study, we applied CFD calculation for the simulation of postcombustion chamber. First, we obtained that the mixing in the chamber is efficient, due to the reacting zone, which is located at the beginning of the reactor. Particularly, we focused on the importance of the gap size. When the gap size was set to 30 and $40 \mathrm{~cm}$, thanks to the oxygen content, the conversion rate of hydrogen and carbon monoxide was high and the oxidation is complete. In addition, we also obtained that the thermal efficiency decreases when the gap size is larger, however the reduction is not significant. Therefore, larger gap size is desirable in practice to avoid the carbon monoxide and hydrogen escape to the ambient. 


\section{References}

[1] M. Kirschen, V. Velikorodov, H. Pfeifer, Mathematical modeling of heat transfer in dedusting plants and comparison to off-gas measurements at electric arc furnaces, Energy, 31, pp. 2926-2939, 2006.

[2] Yun Li, Richard J. Fruehan, Computational Fluid-Dynamics Simulation of Post combustion in the Electric-Arc Furnace, Metallurgical and Materials Transactions B, 34B, pp. 333-343, 2003.

[3] P. Gittler, R. Kickinger, S. Pirker, E. Fuhrmann, J. Lehner, J. Steins, Application of computational fluid dynamics in the development and improvement of steelmaking processes, Scandinavian Journal of Metallurgy, 29, pp. 166-176, 2000.

[4] K. Chattopadhyay, M. Isac, R. I. L. Guthrie, Application of Computational Fluid Dynamics (CFD) in iron- and steel making: Part 1, Iron making and Steel making, 37(8), pp. 554-561, 2010.

[5] K. Chattopadhyay, M. Isac, R. I. L. Guthrie, Application of Computational Fluid Dynamics (CFD) in iron- and steel making: Part 2, Iron making and Steel making, 37(8), pp. 562-569, 2010.

[6] D. Mazudmar, J. W. Evans, Modelling of steelmaking processes, Boca Raton, FL, CRC Press, 2009.

[7] A. Habibi, B. Merci, G. J. Heynderickx, Impact of radiation models in CFD simulations of steam cracking furnaces, Computers and Chemical Engineering, 31, pp. 1389-1406, 2007.

[8] A. Cuoci, A. Frassoldati, G. Buzzi Ferraris, T. Faravelli, E. Ranzi, The ignition, combustion and flame structure of carbon monoxide/hydrogen mixtures, Note2: Fluid dynamics and kinetic aspects of syngas combustion, International Journal of Hydrogen Energy, 32, pp. 3486-3500, 2007.

[9] Magnussen B.F, On the structure of turbulence and a generalized Eddy dissipation concept for chemical reactions in turbulent flows. 19 ${ }^{\text {th }}$ AIAA aerospace science meeting, St. Louis, Missouri, 1981.

[10] Y. R. Sivathanu \& G. M. Faeth. Generalized State Relationships for Scalar Properties in Non-premixed Hydrocarbon/Air Flames, Combustion and Flame, 82, pp. 211-230, 1990.

[11] L. Labiscsak, G. Straffelini, F. Trivellato, M. Bodino, C. Corbetta, Computational fluid dynamics simulations of post combustion chambers, $33^{\text {th }}$ AIM National Congress, Brescia, Italy, 2010.

[12] G. Krishnamoorthy, A new weighted-sum-of-gray-gases model for $\mathrm{CO}_{2}$ $\mathrm{H}_{2} \mathrm{O}$ gas mixtures, International Communications in Heat and Mass Transfer, 37, pp. 1182-1186, 2010. 